\title{
Lightweight Heat Resistant Geopolymer-based Materials Synthesized from Red Mud and Rice Husk Ash Using Sodium Silicate Solution as Alkaline Activator
}

\author{
Nguyen Hoc Thang ${ }^{1, *}$, Pham Trung Kien ${ }^{2}$, and Mohd Mustafa Al Bakri Abdullah ${ }^{3}$ \\ ${ }^{1}$ Faculty of Chemical Technology, Ho Chi Minh City University of Food Industry, 140 Le Trong Tan Str, \\ Tan Phu Dist., Ho Chi Minh City, Viet Nam \\ ${ }^{2}$ Faculty of Materials Engineering, Ho Chi Minh City University of Technology, 268 Ly Thuong Kiet Str, \\ Dist. 10, Ho Chi Minh City, Viet Nam \\ ${ }^{3}$ Center of Excellence, Geopolymer \& Green Technology (CeGeoGTech), School of Material \\ Engineering, Universiti Malaysia Perlis (UniMAP), Perlis Malaysia
}

\begin{abstract}
Geopolymer is an inorganic polymer composite with potentials to replace Ordinary Portland Cement (OPC)-based materials in the future because of its lower energy consumption, minimal $\mathrm{CO}_{2}$ emissions and lower production cost as it utilizes industrial waste resources. Hence, geopolymerization and the process to produce geopolymers for various applications like building materials can be considered as green industry. Moreover, in our study, the raw materials we used are red mud and rice husk ash, which are are industrial and agricultural wastes that need to be managed to reduce their impact to the environment. The red mud and rice husk ash combined with sodium silicate (water glass) solution were mixed to form geopolymer materials. Moreover, the geopolymer specimens were also tested for heat resistance at a temperature of $1000^{\circ} \mathrm{C}$ for 2 hours. Results suggest high heat resistance with an increase of compressive strength after exposed at high temperature.
\end{abstract}

\section{Introduction}

Geopolymer, as coined by Davidovits [1], is an inorganic polymer composite which has a potential sustainable construction material because of its lower energy and carbon footprint as compared to Portland cement-based materials [2]. Such material uses industrial waste such as red mud as raw material which reduce its cost of production. Red mud (RM) is the waste generated during aluminum production from bauxite ore. It depends on the quality of bauxite mine which could affect the output of aluminum production. To produce 1 ton of metallic aluminum, this Bayer process generates from 0.6 - 2.5 tonnes of red mud [3-4]. Globally, it is estimated that there has been over 70 million tonnes of this red mud (RM) waste being discharged every year $[4,5]$. RM waste is fine powder and thus easy to disperse into the

\footnotetext{
*Correspoding author : thangnh@entp.edu.vn
} 
surrounding environment which may lead to ecological problems. Currently, RM is contained in dams but these use up a lot of land area. Moreover, these dams pose risk to surrounding residential areas. In fact, in 2010, an accident wherein the failure of red mud dam occurred in Hungary caused serious environmental consequences and health impact to people $[3,7]$. Therefore, it is imperative to manage these red mud wastes properly to reduce its impact to environment and community.

In the other hand, rice husk ash (RHA) is high-silica material made from burning rice husk. Rice husk takes up about $20 \%$ weight of rice and its compositions include $15-20 \% \mathrm{SiO}_{2}$, the others are cellulose and lignin $[8,9,10]$. After the burning process, total weight of obtained RHA is about $20 \%$ weight of rice husk. Hence, the total estimated RHA reserves are over 28 million metric tons every year [9].

\section{Materials and methods}

In this research, both red mud (RM) and rice husk ash (RHA) from Vietnam were used to produce the geopolymer mixture. They are the raw materials in geopolymerization reactions to create the mechanical strength for product. All of the raw materials were characterized before carrying out the mixing to form the geopolymer mortar. The red mud contains high alumina in amorphous or semi-crystalline structure which serves as one of the reactants in the geopolymerization process. RM waste came from Tan Rai Bauxite Plant, Lam Dong Province, Vietnam and its chemical composition is summarized in Table 1. On the other hand, rice husks from Mekong delta, South of Viet Nam were burned at $700^{\circ} \mathrm{C}$ for 1 hour at Laboratory of Ceramic Materials to obtain rice husk ash with chemical compositions described in the same table.

Table 1. Chemical composition of raw materials from Vietnam

\begin{tabular}{|c|c|c|c|c|c|c|c|c|c|}
\hline \multirow{2}{*}{$\begin{array}{c}\text { Raw } \\
\text { materials }\end{array}$} & $\mathrm{SiO}_{2}$ & $\mathrm{Al}_{2} \mathrm{O}_{3}$ & $\mathrm{Fe}_{2} \mathrm{O}_{3}$ & $\mathrm{CaO}$ & $\mathrm{Na}_{2} \mathrm{O}$ & $\mathrm{K}_{2} \mathrm{O}$ & $\mathrm{TiO}_{2}$ & Other & L.O.I \\
\hline Red mud & 4.52 & 18.98 & 49.90 & 0.87 & 2.06 & 0.05 & 5.62 & 1.48 & 16.52 \\
\hline $\begin{array}{c}\text { Rice husk } \\
\text { ash }\end{array}$ & 90.90 & 1.12 & 0.54 & 1.41 & - & 4.66 & - & 0.06 & 0.77 \\
\hline
\end{tabular}

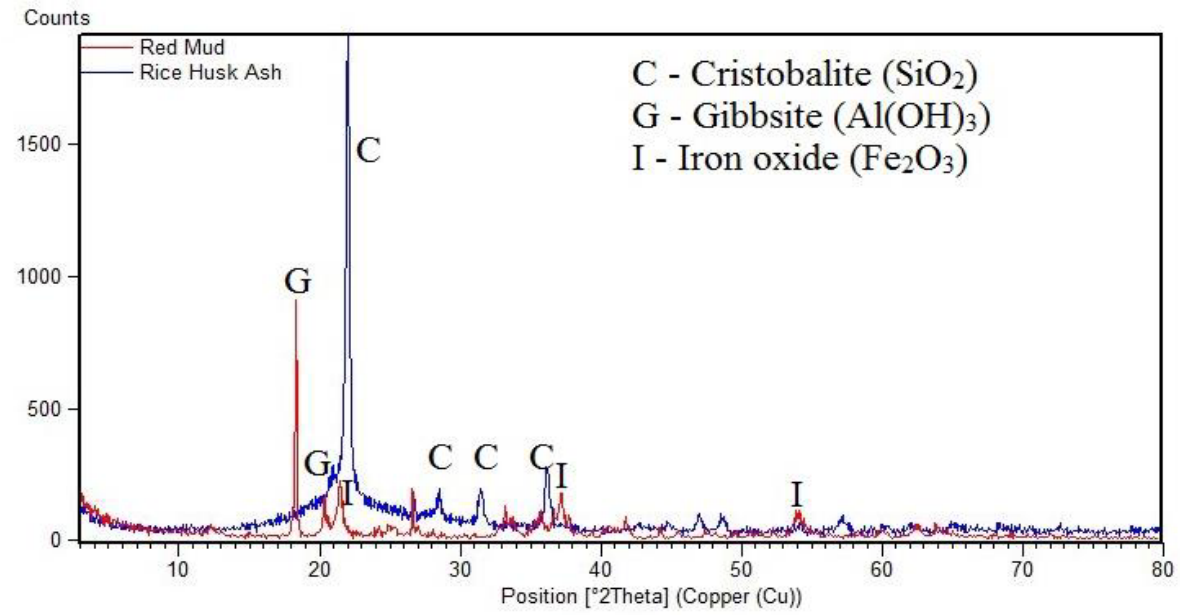

Fig. 1. XRD patterns of red mud and rice husk ash 
As shown from the XRD of red mud and RHA, evidence of amorphous silica and alumina was observed as described by the noise at the bottom hump of the XRD spectrums (see Figure.1). There also have been some sharp peaks associated with crystalline minerals of gibbsite $\left(\mathrm{Al}_{2} \mathrm{O}_{3} .3 \mathrm{H}_{2} \mathrm{O}\right)$ at $18^{\circ}$ and iron oxide $\left(\mathrm{Fe}_{2} \mathrm{O}_{3}\right)$ at $20^{\circ}$ in XRD pattern of $\mathrm{RM}$ (Figure.1) and cristoballite $\left(\mathrm{SiO}_{2}\right)$ in XRD spectrum of RHA (Figure.1). Note that the amorphous compositions are necessary conditions to conduct geopolymerization for RM based geopolymer materials. Water glass solution was then used as alkaline solution to increase $\mathrm{pH}$ value and supply the sodium hydroxide reactant for the geopolymer mixtures.

Table 2 summarizes the mix proportions used in this experiment. The schematic diagram of the experimental process is shown in Figure 2. RM, after being dried for 24 hours, was ground in 30 minutes (Ceramic Instrument) and then passed through $90 \mu \mathrm{m}$ - mesh (Retsch AS-200 Seive Shaker). Rice husk was burned at $700^{\circ} \mathrm{C}$ for one hour (NABERTHERM), and then also ground in 30 minutes and passed through $90 \mu \mathrm{m}$-mesh. All raw materials were mixed for 20 minutes with $20 \%$ water glass solution (Lab cement mixer) and water is added to get a $\mathrm{pH}$ value around 12 . Geopolymer mixtures were molded in 50x50x50mm cube-cement mold and cured at room temperature $\left(28^{\circ} \mathrm{C}, 80 \%\right.$ humidity). The 28 -day geopolymer specimens were tested for compressive strength, volumetric weight, and heat resistance. Then, the geopolymer specimen with the highest value of compressive strength was characterized with X-ray diffraction.

Table 2. Mix proportions of raw materials

\begin{tabular}{|c|c|c|c|}
\hline & \multicolumn{3}{|c|}{ Proportion (wt.\%) } \\
\hline Sample & Red mud & Rice husk ash & Water glass solution (WGS) \\
\hline A & 20 & 60 & 20 \\
\hline B & 40 & 40 & 20 \\
\hline C & 60 & 20 & 20 \\
\hline
\end{tabular}

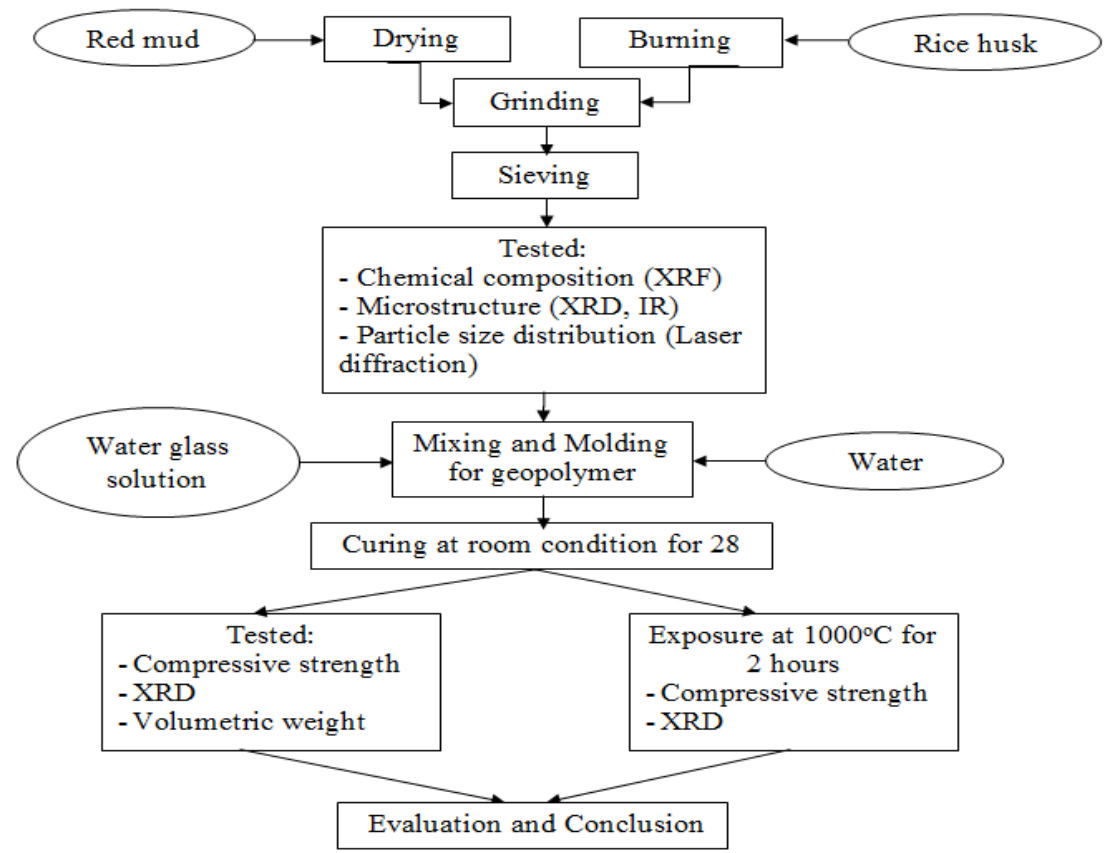

Fig. 2. The experimental process to produce geopolymer-based materials from red mud and RHA. 


\section{Results and discussions}

\subsection{Compressive strength and volumetric weight}

Table 3. Properties of geopolymer produced from red mud and rice husk ash

\begin{tabular}{|c|c|c|c|c|c|c|c|}
\hline \multirow[t]{2}{*}{ Sample } & \multicolumn{3}{|c|}{ Mix Proportions (wt.\%) } & \multirow{2}{*}{$\begin{array}{c}\text { Volumetric } \\
\text { weight } \\
\left(\mathrm{kg} / \mathrm{m}^{3}\right)\end{array}$} & \multicolumn{2}{|c|}{$\begin{array}{l}\text { Compressive strenghth } \\
(\mathrm{MPa})\end{array}$} & \multirow{2}{*}{$\begin{array}{c}\text { Change of } \\
\text { compressiv } \\
\text { e strength } \\
(\%)\end{array}$} \\
\hline & $\mathrm{RM}$ & RHA & WGS & & $\begin{array}{l}\text { Room } \\
\text { condition }\end{array}$ & $\begin{array}{c}\text { After } \\
\text { exposed at } \\
1000^{\circ} \mathrm{C}\end{array}$ & \\
\hline A & 20 & 60 & 20 & 1270 & 15.50 & 67.83 & 337.63 \\
\hline B & 40 & 40 & 20 & 1460 & 8.33 & 30.17 & 262.00 \\
\hline $\mathrm{C}$ & 60 & 20 & 20 & 1590 & 6.83 & 35.33 & 417.07 \\
\hline
\end{tabular}

The volumetric weight of geopolymer specimens were found to be from 1270 to 1590 $\mathrm{kg} / \mathrm{m}^{3}$ (see Table 3). The geopolymer samples were also tested for 28 day- compressive strength and the results showed that the values range from $6.83 \mathrm{MPa}$ to $15.50 \mathrm{MPa}$. In addition, sample $\mathrm{A}$ has the highest value at 15.50 because of the high silica in geopolymer mixture that reacted with alumina of red mud to form the geopolymer networks (see Table 3 ). These values can be compared with concrete brick in ASTM C55 and C90 [13-14]

\subsection{Heat resistance}

All geopolymer samples were tested for heat resistance by keeping the specimen at a furnace at the temperature at $1000^{\circ} \mathrm{C}$ for 2 hours, with a heating rate of $5^{\circ} \mathrm{C} / \mathrm{min}$ and a natural cooling process to room temperature. This procedure is similar to test done by Kong et al., (2007) [11] and Pan et al., (2012) [12]. After exposure with this high temperature, the samples were tested for compressive strength. Results indicate that the compressive strength significantly increased from $262 \%$ to $417 \%$ as shown in Figure 3 and summarized in Table 4 . This could be due to sintering that may be occurred at high temperature in geopolymer samples, similar to what is happening in ceramic process $[11,12]$.

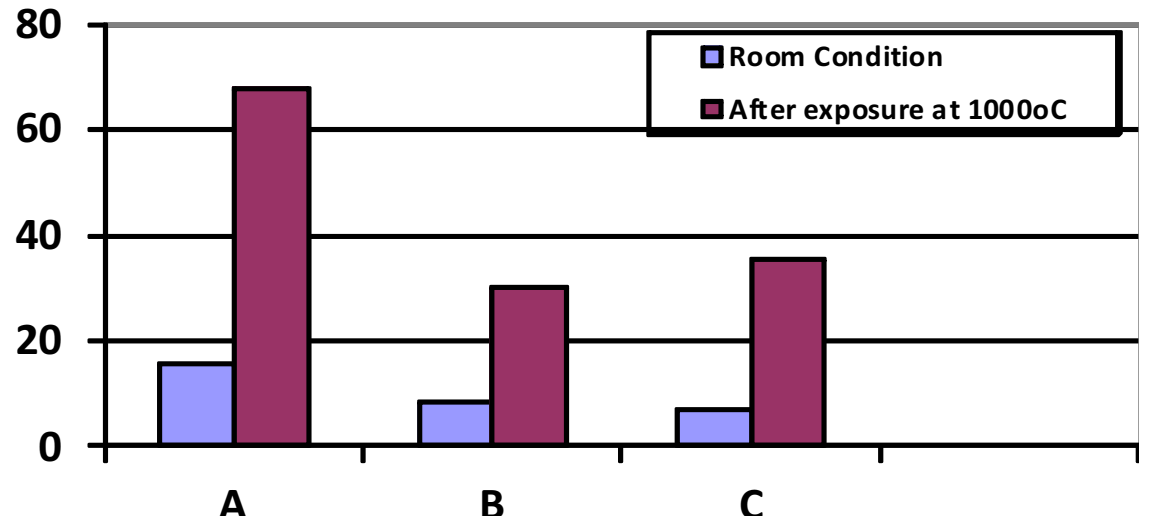

Fig. 3. Compressive strength of geopolymer before and after exposed at $1000^{\circ} \mathrm{C}$. 


\subsection{Microstructure}

Geopolymer sample A has the highest compressive strength and was therefore selected for microstructure characterization by XRD (see Figure 4).

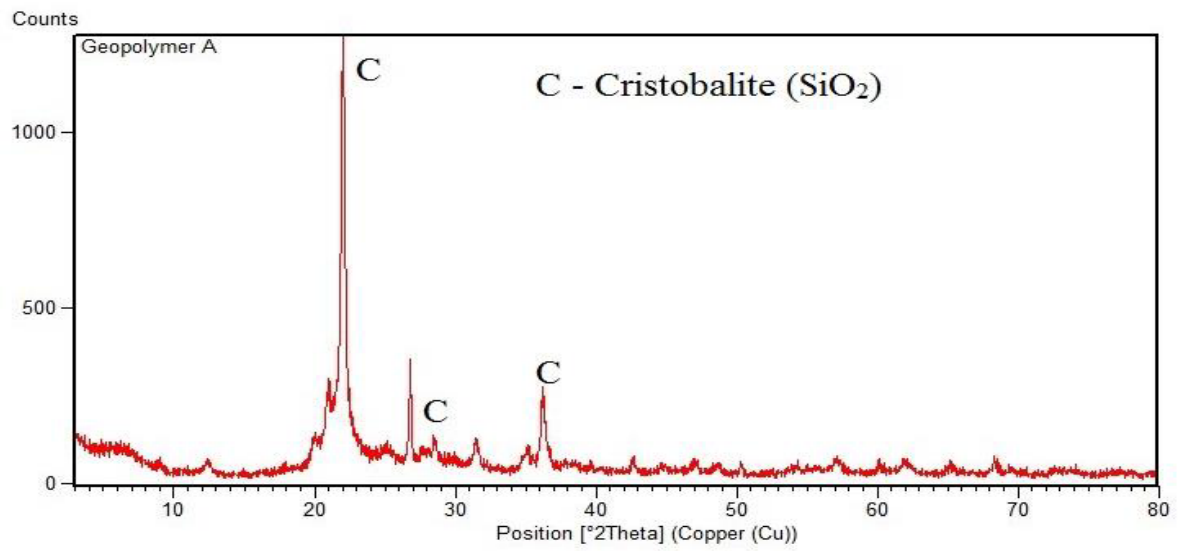

Fig. 4. (Top) XRD pattern of geopolymer sample A

The main compositions in the crystalline structure of geopolymer are silicon oxide (at $22^{\circ}$ 2Theta angle) and some minerals such as sodium aluminium silicate (at $21.5^{\circ}$ - 2Theta angle), iron silicon oxide $\left(36^{\circ}\right.$ - 2Theta angle). Amorphous phase in its microstructure has also been observed. Two peaks of gibbsite and iron oxide at $18^{\circ}-2$ Theta angle and $20^{\circ}$ - 2Theta angle, respectively are typically associated with red mud raw material (Figure 1) disappeared in this $\mathrm{XRD}$ spectrum because there was reaction of geopolymerization among reactants resulting to an increase of mechanical strength of geopolymer specimens.

\section{Conclusions}

Red mud is an industrial waste that can effect negatively the environment if not properly managed. It is necessary to have more research in utilizing this as raw materials for other applications. In this research, red mud in combination with rice husk ash in high alkaline condition can be geopolymerized to form products that can be compared with concrete brick in ASTM C55 and C90 in terms of mechanical strength and volumetric weight. More specially, the geopolymer products have high compressive strength even if exposed at high temperature. That can be evaluated as heat-resistant materials. Future work will be done to characterize further the microstructure and optimize the properties for a lightweight heat-resistant geopolymer material.

Our research group would like to give deep appreciation to Ho Chi Minh City University of Technology, De La Salle University for the provided facility. Also, we would like to thank Tokyo Institute of Technology for the discussions and reference provided. The first author also acknowledge the support of AUNSEED-Net in the conduct of this collaborative research.

\section{References}

1. J. Davidovits, Geopolymer Chemistry and Application (Institute Geopolymere, France, 2011) 
2. Z. Li, Z. Ding, Y. Zhang, Proceedings of the International Workshop on Sustainable Development and Concrete Technology (2004)

3. J. Benedek, Causes and Lessons from the Red Mud Disaster (Greens / European Free Alliance Parliamentary Group in the European Parliament and LMP, Cypress Ltd, 2011)

4. W. Liu, J. Yang, B. Xiao., Int. J. Miner. Process., 93, 220 (2009)

5. S. Amritphale, A. Anshul, N. Chandra, N. Ramakrishnan., J. Eur. Ceram. Soc., 27, 1845 (2006)

6. G. Zhang, J. He., Developments in Strategic Materials and Computational Design II, (John Wiley \& Son, United States, 2011)

7. S. Chandra, Waste Materials Used in Concrete Manufacturing (Noyes, USA, 1997).

8. R. Siddique, M. Khan. Supplementary Cementing Materials (Springer-Verlag Berlin Heidelberg, New York, 2011)

9. B.K.Y. Foo, B.H. Hameed, Adv. Colloid Interface Sci., 152(1), 39 (2003)

10. D. Kong, J. Sanjayan, K.S. Crentsil, Cem. Concr. Res., 37(12), 1583 (2007)

11. Z. Pan, G. Jay, G. Kong, Constr. Build. Mater., 36, 365 (2012)

12. Standard ASTM C55 99, Standard specification for concrete brick.

13. Standard ASTM C90 99a, Standard specification for load bearing concrete masonry units. 